\title{
INTERVENÇÕES NO BAIRRO DO RECIFE E NO SEU ENTORNO: indagações sobre a sua legitimidade
}

\author{
Norma Lacerda*
}

\begin{abstract}
Resumo: O presente artigo tem como objetivos (i) mostrar como a experiência de revitalização do Bairro do Recife foi desvirtuada, aproximando-se da tendência de city marketing, entendida como a aceleração da taxa de transformação de certas localidades, com ênfase especulativa sobre imóveis e grandes obras de renomados arquitetos, com importantes repercussões em termos de trânsito de veículos e fluxos de pessoas, e (ii) questionar sobre a legitimidade de projetos que, embora institucionalmente aprovados, comprometem as características de determinadas estruturas espaciais urbanas, como é o caso dos centros históricos.
\end{abstract}

Palavras-chave: patrimônio histórico, legitimidade espacial, Bairro do Recife.

\section{Introdução}

O presente texto é o resultado de um percurso reflexivo, iniciado com a apresentação de suas primeiras idéias na palestra por mim conferida no I Fórum Nacional sobre Patrimônio Cultural, realizado em Belo Horizonte em 2004. Teve como ponto de partida a seguinte indagação formulada por seus organizadores: Os chamados projetos de reabilitação em curso no Brasil (Pelourinho, Bairro do Recife, dentre outros) estariam, de fato, reabilitando o patrimônio

\footnotetext{
Doutora em Géographie, Aménagement et Urbanisme pela Université Sorbonne Nouvelle - Paris III - Institut des Hautes Études de l'Amérique Latine. Arquiteta, professora do Programa de Pós-Graduação em Desenvolvimento Urbano da Universidade Federal de Pernambuco (UFPE).
} 
das cidades, ou apenas se inserindo na tendência de city marketing? Para responder a essa indagação, optou-se por analisar o caso do Bairro do Recife, considerado, até 1997, uma experiência exitosa de reabilitação ao proporcionar o ressurgimento de um lugar de encontro, mas que, a partir de então, segundo a nossa hipótese, foi desvirtualizado, aproximando-se da tendência de city marketing, entendido como a aceleração da taxa de transformação de certas localidades, com ênfase especulativa sobre imóveis e grandes obras de renomados arquitetos, com importantes repercussões em termos de trânsito de veículos e fluxos de pessoas.

Essas primeiras idéias, transformadas em um trabalho discutido no âmbito do IX Seminário Internacional de la Red Iberoamericana de Investigadores en Globalização y Território, realizado em maio de 2005, em Bahia Blanca (Argentina), finalizava com as seguintes questões que direcionaram o debate: $\mathrm{O}$ que vem acontecendo com o Bairro do Recife é um processo legítimo? É legítimo transformar um lugar de encontro em um espaço de trânsito e de fluxos? Esse debate impulsionou a refletir com mais profundidade sobre a legitimidade de intervenções que descaracterizam o patrimônio histórico e arquitetônico, lançando mais uma hipótese: projetos institucionalmente aprovados que comprometem as características de conjuntos históricos não são legítimos.

A comprovação dessas hipóteses exigiu que o trabalho se desenvolvesse em quatro etapas. Na primeira, retoma-se o contexto dos processos de revitalização dos centros históricos das cidades brasileiras. Na segunda, procura-se revelar como surgiu, no âmbito dos poderes públicos estadual e municipal, a preocupação com a conservação de áreas de interesse histórico, bem como os objetivos da primeira proposta de revitalização do mencionado Bairro. $\mathrm{Na}$ terceira, investigou-se como ocorreu o processo de elaboração e implantação da segunda proposta - o Plano de Revitalização -, chamando a atenção para os acertos e os percalços, para as tensões 
e os conflitos. Percorrido esse caminho, responde-se, na terceira parte, sobre a sua inserção, ou não, na tendência do city marketing. Finalmente, na última - mediante esclarecimentos sobre os conceitos de legalidade e legitimidade - conclui-se que as intervenções que vêm recentemente acontecendo no Bairro, comprometendo as suas principais características arquitetônicas, não são legítimas, mesmo que portadoras de legalidade.

\section{As primeiras idéias ${ }^{1}$}

As primeiras propostas de conservação de áreas de interesse histórico, artístico e cultural tiveram origem, na década de 1970, nos programas de preservação de sítios históricos, devido à grande investida do Serviço do Patrimônio Histórico e Arquitetônico Nacional (SPHAN) e da Fundação Pró-Memória. Tal investida resultou na elaboração, pela Fundação de Desenvolvimento da Região Metropolitana do Recife (FIDEM), do Plano de Preservação dos Sítios Históricos da Região Metropolitana do Recife (PPSH).

Fundamentado nesse Plano de caráter metropolitano, o governante municipal, no início dos anos 1980, mediante a Lei $\mathrm{n}^{\circ}$ 13.957/81, institucionalizou trinta e uma áreas de proteção, dentre elas a do Bairro do Recife.

A aprovação dessa lei, bem como a sua implementação, foi enormemente favorecida pela mudança no padrão de localização das atividades de comércio e serviços, consideradas "nobres", que, até então, se situavam nas áreas centrais da cidade, dentre elas o Bairro do Recife. No entanto, na década de 1970, a dinâmica espacial do mercado imobiliário da cidade alavancou um processo de descentralização dessas atividades. O terciário "nobre" começou a acompanhar espacialmente a sua clientela, tornando o centro do Recife pouco atrativo. 
Tal processo, vivenciado praticamente por todas as metrópoles brasileiras, foi caracterizado pela substituição de antigas estruturas construídas de altíssima qualidade ambiental por estruturas verticalizadas. Os bairros tradicionais do Recife, a exemplo do Espinheiro e das Graças, relativamente bem localizados e bem servidos quanto às infra-estruturas urbanas, foram sendo paulatinamente destruídos, dando lugar a uma ocupação vertical, com uma forte densidade construtiva e populacional. À medida que esses bairros presenciavam alterações no seu modelo de ocupação, o terciário "nobre" foi aí se instalando, abandonando o centro da cidade, criando novas centralidades.

$\mathrm{Na}$ verdade, a área que conformava o centro histórico, particularmente o Bairro do Recife, entrou, na década de 1970, em um ritmo acelerado de degradação ambiental, passando a ser uma "periferia" da cidade. Daí surgiu um paradoxo: o bairro tornou-se uma "periferia" na centralidade. Por não se constituir em uma área de interesse do setor imobiliário, não era, conseqüentemente, alvo de disputas políticas quanto à legislação de uso e ocupação do solo.

O que se viu no Bairro foi a emergência de um capital construído ocioso, caracterizado pela baixa rentabilidade, significando uma desvalorização da riqueza construída, pública e privada. Pior ainda, o Bairro permaneceu como uma lembrança na memória dos cidadãos da metrópole recifense e não mais se materializava enquanto espaço de convivência. A perda do seu valor cultural foi acompanhada da perda do valor social (Lacerda \& Zancheti, 2000).

\section{O Plano de Revitalização do Bairro do Recife ${ }^{2}$}

Na segunda metade da década de 1970, o Prefeito do Recife é eleito a partir de uma aliança política bem próxima dos setores populares. Foi nesse ambiente que o Bairro do Recife obteve um 
tratamento especial, sendo, inclusive, criado o Escritório do Bairro do Recife, e com ele, a primeira proposta para a sua recuperação. $\mathrm{O}$ objetivo dessa proposta era restaurar a memória dos seus habitantes e integrá-los nos processos de elaboração dos projetos de intervenção. Assim, as ações eram essencialmente voltadas para os habitantes das favelas, os empregados do porto e as prostitutas. Nesse cenário, o comportamento dos principais atores econômicos (os dirigentes do porto, os grandes proprietários, os atacadistas, os dirigentes de grupos financeiros, dentre outros) foi afastar-se do processo. Afinal, é de convir que aquele grupo social, caracterizado pelos baixos rendimentos, detinha pouco poder no que se refere ao processo de reprodução da economia do Bairro. Evidentemente, embora coerente com o discurso político do governante, essa proposta pouco significou no sentido de reverter o processo de degradação física.

No final da década de 1980, o Governo do Estado de Pernambuco, elaborou um ambicioso Plano para transformar a economia estadual, sendo um dos seus pilares o crescimento do setor turístico. É exatamente nesse contexto que, em 1992, é desenvolvido o Plano de Revitalização do Bairro do Recife, uma das propostas para compor o Programa Integrado de Desenvolvimento do Turismo do Nordeste (Prodetur), gerenciado pelo Banco do Nordeste do Brasil (BNB), com recursos do Banco Interamericano de Desenvolvimento (BID).

Nesse mesmo ano, o Prefeito foi reeleito e, com ele, as propostas de intervenção no Bairro ganharam um novo impulso. A aproximação política entre o Governador e o Prefeito foi decisiva para que a implantação do Plano passasse a ser de responsabilidade da Prefeitura do Recife.

O Plano diferenciava-se da primeira proposta. Além de conservar o patrimônio histórico e cultural, tinha como objetivo transformar a economia do Bairro, tornando-o um centro regional 
de serviços modernos, de comércio, de lazer e de cultura para a população da cidade, e centro de atração turística nacional e internacional. Para tanto, deveria adotar um modelo de gestão capaz de assegurar um desenvolvimento sustentável.

Quanto à organização espacial, o Plano define quatro setores, sendo que dois foram posteriormente (1995-1996) agrupados quando da realização dos estudos que fundamentaram o modelo de regulação, resultando em três setores, conforme a Figura 1 .

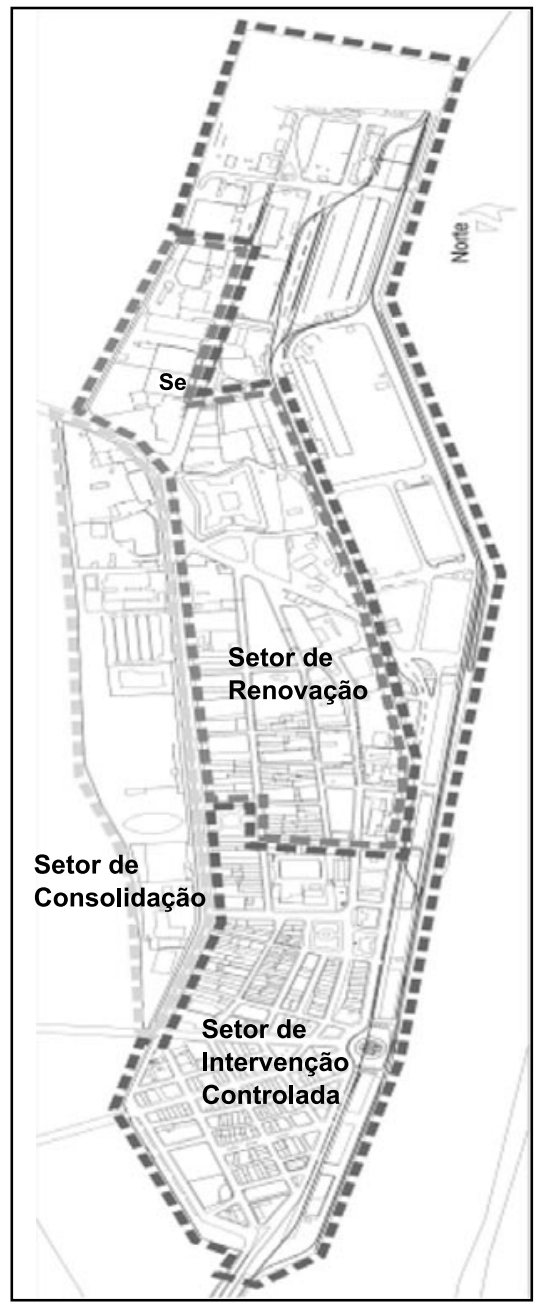

Figura 1 - Bairro do Recife - Configuração espacial

Fonte: Marinho, G., 1998. 
O Setor de Intervenção Controlada abriga um conjunto edificado, com composição estilista de influência francesa, e toda a área de domínio do porto, sendo que esta área, de acordo como o Plano, conformava um único setor. O Setor de Renovação Urbana seria destinado para os empreendimentos públicos e privados de renovação de infra-estrutura e de patrimônio imobiliário. O Setor de Consolidação Urbana deveria abrigar instituições públicas, como já ocorria antes mesmo da elaboração do Plano de Revitalização (Marinho, 1998, p. 41-43).

Mas o grande desafio para a implementação desse Plano era como induzir o setor privado a investir no Bairro do Recife. Para tanto, definiram-se duas estratégias: (i) concentrar os esforços iniciais em uma única área, apostando em que, com a sua recuperação, os investimentos transbordariam os seus limites, e (ii) induzir o setor privado a acreditar no potencial econômico do Bairro, de tal forma que ali investisse o seu capital.

Como o Plano definia projetos estruturadores, a concentração dos esforços iniciais ocorreu em um desses projetos: o Centro de animação cultural, lazer e comércio do Pólo Bom Jesus, situado na área mais central da ilha.

Quanto ao processo de indução do setor público, Zancheti e Lacerda (1998, p. 101-103) identificaram que ele ocorreu a partir das quatros fases abaixo descritas.

A primeira fase (primeiro semestre de 1992) correspondeu à recuperação dos espaços públicos degradados, mediante (i) intervenções do governo municipal em melhorias das calçadas, iluminação, drenagem e abastecimento d'água; (ii) a decisão de iniciar o processo de abertura da Avenida Alfredo Lisboa, permitindo que o bairro se tornasse uma área de circulação da cidade; e (iii) a recuperação da ponte Maurício de Nassau. Assim, nessa fase, os investimentos extrapolaram os limites do Pólo Bom Jesus e 
visaram, essencialmente, mostrar o compromisso assumido pela administração local.

Na segunda fase (segundo semestre de 1992), o governo municipal (i) foi em busca de parceiros privados com vista à adoção das praças, incluindo a sua recuperação e manutenção; (ii) iniciou as obras de abertura da Avenida Alfredo Lisboa; e (iii) aceitou a proposta da Fundação Roberto Marinho de implantar o Projeto Cores da Cidade, cujo objetivo era a recuperação de fachadas com tintas fornecidas por uma grande empresa internacional. Por meio desse projeto, várias fachadas da Rua do Bom Jesus deveriam ser recuperadas. Mesmo com todas essas realizações, o projeto não deslanchava. Poucas foram as adesões ao Cores da Cidade. A Rua do Bom Jesus ainda apresentava um elevado grau de degradação. $\mathrm{O}$ setor privado não se decidia a recuperar os imóveis e a investir em atividades econômicas.

Assim, a terceira fase (1994 e primeiro semestre de 1995) foi a mais crítica: era necessário reverter a situação caracterizada pela falta de credibilidade no projeto. Para tanto, a municipalidade resolveu ampliar a área geográfica do Projeto Cores da Cidade, iniciar as obras de recuperação do espaço público e, o mais importante, desapropriar cinco edificações na Rua do Bom Jesus, cujos proprietários não queriam recuperar as fachadas.

A quarta fase (1995 e 1996) correspondeu ao período de consolidação do processo de revitalização. A finalização das obras de recuperação do espaço público da Rua do Bom Jesus, o início da recuperação dos imóveis desapropriados e a recuperação da Associação Comercial e da Bolsa de Valores contribuíram, decisivamente, para a adesão dos investidores ao Cores da Cidade. Em 1995, são inaugurados os primeiros bares e restaurantes.

Nesse mesmo ano, iniciaram-se, como comentado, os estudos para a definição do modelo de regulação que serviriam de base 
para a elaboração do Projeto de Lei que institucionalizou o uso e a ocupação do solo no Bairro do Recife. O texto foi submetido a intensas discussões e adequações, culminando na Lei $\mathrm{n}^{0} 16.290$, aprovada pela Câmara Municipal do Recife em 1997.

Ainda nesseano, o BID encomendou uma pesquisa (coordenada por Sílvio Zancheti, com participação da autora do presente texto) sobre o Desempenho do Plano de Revitalização do Bairro do Recife (Zancheti \& Lacerda, 1998). A pesquisa foi concluída salientando o êxito do projeto. Os investimentos em recuperação de imóveis ultrapassavam os limites do Pólo Bom Jesus, e a participação do setor privado, em termos do montante de recursos financeiros, correspondeu, aproximadamente, à mesma quantia investida pelo setor público.

O estudo concluiu que, além do êxito de parceria entre o setor público e o privado, a área surgiu como o orgulho dos recifenses e, portanto, fortaleceu a identidade da cidade. Acrescente-se ainda que, ao se transformar em um espaço de encontro, passou a exercer um poder de atração em termos de investimentos privados.

\section{As tensões e os conflitos}

Em 1997, o município do Recife começou a ter um novo governante. Durante a sua gestão, o Escritório de Revitalização do Bairro Recife, responsável pela implementação do Plano, passou a atuar, quase que exclusivamente, como uma entidade organizadora dos eventos que se realizavam no Bairro.

Embora contando com um Plano e uma Lei de Uso e Ocupação do Solo, o processo de revitalização iria conhecer momentos de tensões e conflitos, cujos resultados vêm contribuindo para um preocupante contraste social e para uma acelerada descaracterização do patrimônio histórico, artístico e cultural. Esses resultados 
relacionam-se com a existência de uma periferia no coração do Bairro e com a sua paulatina transformação em um espaço de trânsito e de fluxos.

\section{Uma periferia na centralidade histórica}

Se o Pólo do Bom Jesus se configurou até os finais da década de 1990 como uma experiência exitosa em termos de revitalização, a ausência de ações em relação ao Pólo Pilar vem ocasionando problemas sociais: a pior periferia do Recife, a Comunidade do Pilar, encontra-se encravada na área de renovação urbana do Plano de Revitalização. Pior periferia porque apresenta os piores índices de inclusão social da cidade (saúde, educação, desemprego...). Nela, vivem, aproximadamente mil pessoas em péssimas condições de habitabilidade (ver quadro 1). Não é à toa a sua denominação original: Favela dos Ratos. O que se vê é uma periferia na centralidade histórica.

\section{Quadro 1 - Comunidade do Pilar: informações socioeconômicas}

\begin{tabular}{|l|r|}
\hline Área & 2 hectares \\
\hline População & 1.052 habitantes \\
\hline Número de Habitações & 463 unidades \\
\hline Esgotamento sanitário & Inexistente \\
\hline Localização dos imóveis & $82 \%$ em logradouros públicos \\
\hline Renda familiar & $75 \%$ com até 2 salários mínimos \\
\hline Local de trabalho & $72 \%$ trabalham na área ou entorno \\
\hline Escolaridade & $32 \%$ analfabetos \\
\hline Saúde & Coeficiente $17.6 / 10.000$ (tuberculose) \\
\hline
\end{tabular}

Fonte: Prefeitura do Recife, 2002.

Convém registrar que o Plano previa um outro projeto estruturador, o Centro Múltiplo do Pilar, para a instalação de um 
centro de atividades de apoio às atividades do porto, devendo abrigar comércio, serviços e habitação. Quanto à Favela dos Ratos, deveria ser relocada. Afinal, quando da realização do Plano, apenas algumas famílias, que prestavam algum tipo de serviço ao porto, ocupavam a área. Esse projeto estruturador não deslanchou e, com o aumento do número de famílias, a relocação passou a ser questionada. Mais recentemente (2002), o governo municipal desenvolveu o projeto de urbanização de forma a garantir a permanência dessa população. Decisão pertinente, uma vez que parte expressiva das famílias (75\%) viabilizam os seus rendimentos no próprio Bairro.

Chama a atenção o fato de essa comunidade localizar-se a, aproximadamente, duzentos metros do Edifício Sede da Prefeitura do Recife, um dos prédios públicos que integram o setor de consolidação e, também, do complexo de edificações que configuram o Porto Digital que, como se verá adiante, desenvolve a atividade considerada como o símbolo maior da globalização.

Acrescente-se, ainda, o caso da Ponte do Limoeiro que, em 1999, foi recuperada. Só que, embaixo da ponte, mais precisamente no seu "sótão", permaneceram morando 18 famílias, conformando uma favela, batizada pelo pertinente nome de Favela do Morcego. Ninguém as via, estavam escondidas. Ação típica de embelezamento para o turista descortinar a bela paisagem panorâmica do centro do Recife. Em 2002, o então prefeito, relocou essas famílias para uma área próxima, situada no Bairro de Santo Amaro.

A transformação do lugar de encontro em espaço de trânsito efluxos

Não é nenhuma novidade que as grandes cidades brasileiras enfrentam o desafio de se inserirem no processo de globalização. Dar às costas à globalização é uma decisão política irresponsável, fadada ao fracasso, uma vez que se trata de um processo econômico 
irreversível. Segundo Lacerda e Zancheti (2000, p. 84), a globalização pode acarretar uma rápida perda de identidade das cidades, a não ser que cada uma consiga formar processos específicos de geração de valor que não possam ser reprodutíveis nas demais, de tal forma que se diferenciem umas das outras mediante uma estratégia que signifique o reforço das especificidades locais para que a diferença possa tornar-se valor. A cidade que consegue criar e fazer reconhecer as suas especificidades, passa a agregar valor à sua produção local, independentemente do setor econômico no qual esteja atuando.

Foi exatamente no contexto da globalização que emergiram no Brasil, particularmente a partir da década de 1990, as propostas de revitalização de centros históricos e com elas o grande risco de descaracterização, uma vez que as referências, muitas vezes, são as internacionais. A visão dominante inscreve-se sob a lógica econômica da construção de nichos de mercado para os centros históricos, particularmente para os serviços de nova geração. Com isso, segundo Fernando Carrión (2001, p. 31), muda-se o conteúdo da centralidade do centro histórico:

De espaço de encontro para lugares de trânsito e fluxos. Para tanto, existe a necessidade de se vencer a barreira que significa a centralidade histórica para a circulação de pessoas, bens e serviços e informação. Valoriza-se mais a mobilidade da população, informação e recursos do que as necessidades de encontro e formação da comunidade. Por isso, nos centros históricos, a população residente é menor e o turista tem maior importância, apesar de ser minoria.

Daí decorre, segundo Carrión (2001, p. 32) uma das maiores tensões: aquela entre a centralidade histórica e a centralidade urbana. É exatamente no marco da crise da centralidade histórica que se buscou recuperar a centralidade urbana. Daí a importância das políticas públicas urbanas no sentido de fortalecerem a centralidade histórica, com todo o seu significado e simbolismo, senão haverá o enorme risco de se resgatar apenas a centralidade urbana. É o que, de certa forma, vem ocorrendo com o Bairro do Recife. 
Em 2000, a Secretaria de Ciência, Tecnologia e Meio Ambiente (Sectma), do Governo do Estado de Pernambuco, lança o Projeto Porto Digital Empreendimentos e Ambiente Tecnológico. Trata-se de um sistema local com foco no desenvolvimento de software. Atualmente, conta com 68 instituições, entre empresas de TCI, serviços especializados e bancos de fomento. Os recursos de 33 milhões de reais do Governo do Estado vêm sendo utilizados para criar a infra-estrutura e as condições necessárias para a implantação e a operacionalização do projeto, cuja missão é inserir Pernambuco no centro tecnológico mundial. A área para a localização desse parque tecnológico foi o Bairro do Recife. A própria Sectma, "âncora" do projeto, recuperou uma importante edificação no Bairro para ali se sediar. A instalação das demais instituições configurou um complexo de edificações para a tecnologia da informação. Sem dúvida, tal iniciativa tem sido importante em termos de recuperação de vários imóveis deteriorados.

Paralelamente às atividades do Complexo Porto Digital, outras foram e vêm sendo instaladas, particularmente na área sul do Bairro. $\mathrm{O}$ antigo prédio do Cais da Alfândega, situado em área institucionalizada pelo Iphan como patrimônio histórico nacional, foi recuperado por meio do Projeto Monumenta BID e, nele, instalado o Shopping Paço Alfândega, concebido como os tradicionais shoppings centers, ou seja, direcionado para os segmentos mais elevados da estrutura social, cujo meio de transporte é o veículo particular.

Assim, para o seu funcionamento, tornava-se necessária uma área que servisse como estacionamento, ou seja, um edifíciogaragem. Esse não poderia ser no subsolo, por conta das suas condições geológicas. Poderia ter sido construído fora da ilha, no Cais de Santa Rita, sendo operado com o apoio de pequenos ônibus circulares. Mas não, foi construído ocupando duas áreas até então 
desocupadas: áreas nobres da ilha, uma com vista para o mar; a outra, para o Rio Capibaribe (Figura 2).

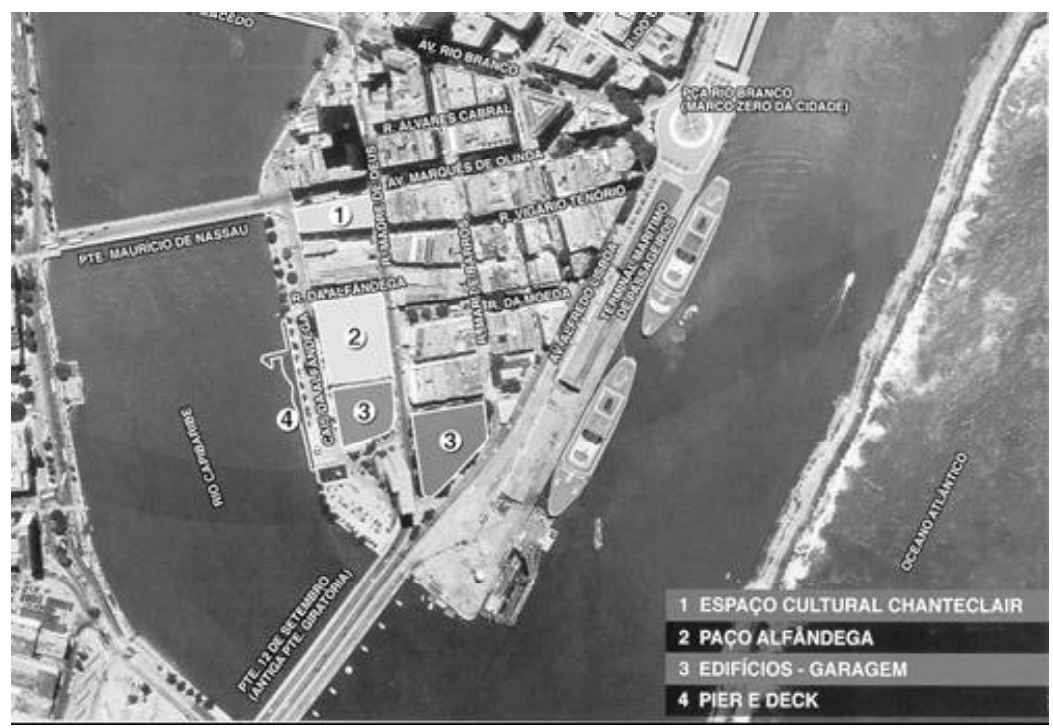

Figura 2 - Área sul do Bairro do Recife.

Fonte: Prefeitura do Recife, 2002.

O mais grave: essas duas áreas foram articuladas, atravessando a Rua da Madre de Deus, por meio de uma passarela de concreto armado, com três andares e com mão dupla para os veículos. Duas questões chamam a atenção: essas áreas tão nobres passaram a abrigar a atividade urbana menos nobre de uma cidade, a guarda de veículos, e a perspectiva da rua da Madre de Deus foi irreparavelmente comprometida.

O Shopping Paço Alfândega tem como principal "âncora" a Livraria Cultura. Além disso, o último pavimento do edifíciogaragem foi ocupado, dentre outras, pela maior empresa de eventos da cidade (a Arcádia), que oferece suporte às cerimônias de casamento dos membros da elite local, celebradas na Concatedral da Madre de Deus e festejadas nas instalações dessa empresa. 
A solução desse edifício-garagem, concebida a partir dos princípios da arquitetura moderna por um arquiteto paulista reconhecido nacionalmente, desconheceu os atributos espaciais do Bairro do Recife, ou seja, não foi precedida de uma análise qualitativa mediante uma leitura morfo-tipológica. Preocupado, muito mais, em destacar/valorizar o seu projeto, não realizou um estudo das características arquitetônicas do entorno. O resultado foi uma edificação que descaracterizou consideravelmente o conjunto histórico e arquitetônico, representando uma perda irreversível para o patrimônio histórico nacional.

A Figura 3 comprova a afirmativa acima. Ao lado do Paço Alfândega, destaca-se um bloco esbranquiçado e pesado que chama para si todas as atenções. $\mathrm{O}$ arquiteto atingiu os seus objetivos. $\mathrm{Na}$ Figura 4, as passarelas de veículos comprometem a perspectiva da Rua da Madre de Deus, onde o campanário da Concatedral se perde debaixo da massa cinza de concreto.

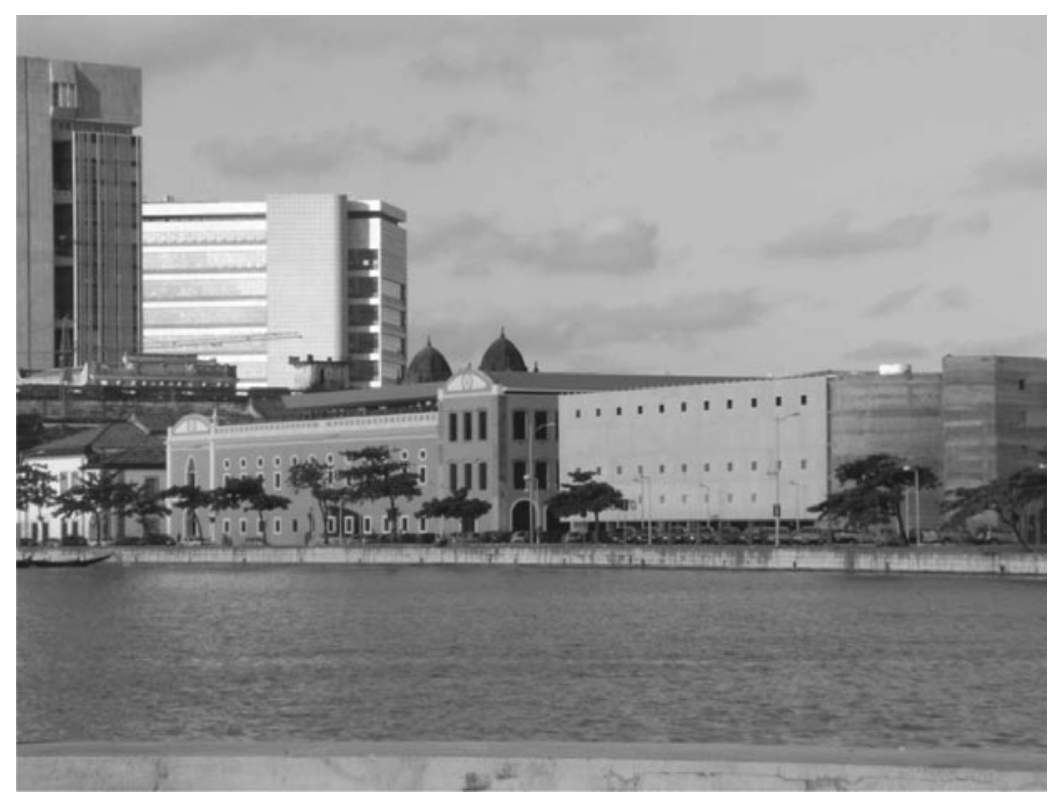

Figura 3 - Edifício-garagem, vista do Rio Capibaribe - 2005 


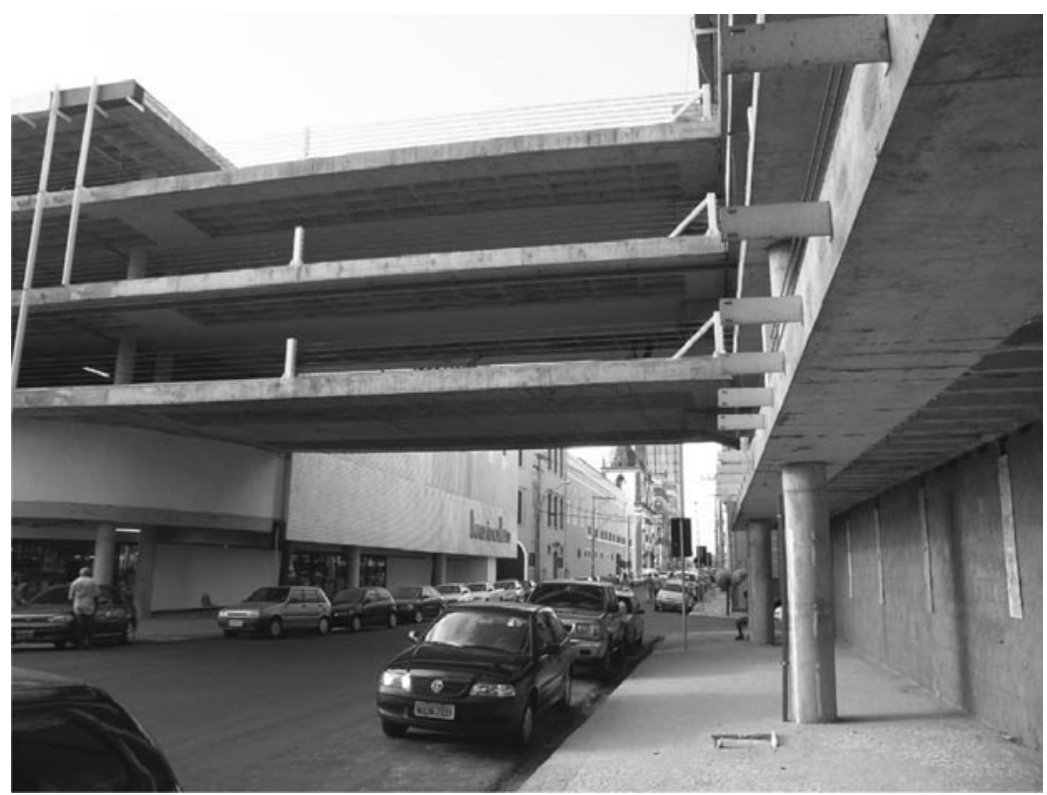

Figura 4 - Edifício-garagem, vista da R. Madre de Deus - 2005

Não poderia ter sido de outra forma. Afinal, esse monumento, patrimônio nacional, foi considerado pelo renomado arquiteto como uma “igrejinha." Talvez ele desconheça que a Madre de Deus está para os recifenses assim como a Notre-Dame está para os parisienses. Sobre o assunto, o poeta Marcus Accioly, em crônica publicada no Jornal do Commercio, no dia 28 de agosto de 2003, escreveu acertadamente:

Na falta do padre Cícero, ou de Antônio Conselheiro, o projeto, em área de preservação rigorosa, tenta provar até ao papa que não se trata de um absurdo e, se não o consegue, é porque a estrutura quadrada do desenho - sombra de concreto armado - já pesa contra a igreja da Madre de Deus que, mesmo sendo - à Carlos Pena Filho - uma "Concatedral" não mais verá o "céu visível" e, depois da obra, só poderá ser vista de avião ou, de cima das passarelas, de automóvel. (...) Se o leitor já sonhou com os Jardins Suspensos da Babilônia, vai acordar sob as ruas suspensas do Recife, com, cada uma, $8,60 \mathrm{~m}$ por 
17,00m. Canta Caetano Veloso - Sampa: "Da força da grana que ergue / e destrói coisas belas". No Recife - mauricéia desvairada e não paulicéia desvairada - a força-grana constrói coisas feias nas belas. A cidade perderá a sua perspectiva, sua visão longitudinal, sua paisagem - céu, rio, mar - para, no próximo carnaval, ter uma aérea Sapucaí: As Passarelas do Paço (ou do passo) da Alfândega - com a restauração do corso. Mas nem tudo está perdido. Quem sabe se, no futuro, um outro Osama bin Laden..."

Infelizmente, o projeto foi aprovado em todas instâncias: Instituto do Patrimônio Histórico e Artístico Nacional (Iphan Nacional), Iphan Regional, Comissão de Controle Urbanístico (CCU) do Recife e Conselho de Desenvolvimento Urbano do Recife (CDU).

No caso do Iphan Regional, seu primeiro parecer foi contrário. Provavelmente, por conta de pressões políticas/econômicas, o posicionamento dessa instituição de defesa do patrimônio histórico e artístico nacional tenha sido revertido, tendo como resultado a aprovação do projeto. No caso do Iphan Nacional, é estranho que o parecerista se tenha respaldado nos exemplos de Brasília e de Diamantina para se posicionar a favor do projeto. Ora, o projeto de Brasília, que desde a sua origem previa passarelas para pedestres, unindo os ministérios aos seus anexos, partiu de uma concepção modernista, e a passarela de pedestre de Diamantina integra o seu conjunto histórico e arquitetônico. Quanto à Comissão de Controle Urbanístico (CCU) e ao Conselho de Desenvolvimento Urbano do Recife (CDU), a maioria dos seus membros, respaldada no parecer do Iphan Nacional e pressionada pelos interesses dos empreendedores, não ousou posicionar-se contra o projeto.

O processo não foi simples. A imprensa noticiava as posições divergentes das duas forças políticas, que se confrontavam no seio do CDU. De um lado, os representantes dos movimentos populares, das Organizações Não-Governamentais e da Universidade Federal 
de Pernambuco posicionaram-se contra a intervenção. Do outro, os representantes da municipalidade, dos setores econômicos (dentre eles, a Associação das Empresas do Mercado Imobiliário - AdemiPE -, Sindicato das Industrias da Construção Civil - Sinduscon -, Clube de Diretores Logistas) e das categorias profissionais (dentre elas, o Conselho Regional de Engenharia, Arquitetura e Agronomia - Crea-Regional -, e o Instituto dos Arquitetos do Brasil - IAB-PE) defendiam a implantação do projeto.

Além disso, as discussões extrapolaram o âmbito das entidades com representação nesse Conselho. O edifício-garagem foi objeto de discussão no Conselho Municipal de Cultura, que se pronunciou contra a intervenção, muito embora não detivesse competência institucional para se pronunciar a respeito da matéria.

Em relação ao posicionamento do IAB-PE e do Crea Regional, não é de se estranhar, uma vez que, no Recife, há algum tempo se vem delineando uma ruptura bastante nítida entre os arquitetos e os planejadores urbanos. Os arquitetos, preocupados com o seu nicho de trabalho, não se contrapõem aos interesses econômicos, particularmente os defendidos pelo setor imobiliário, mesmo se esses interesses representem uma perda para a cidade, seja em termos de paisagem, qualidade de vida, seja de memória urbana. Vale tudo.

Resta comentar sobre o Chantecler, importante edificação histórica próxima ao Shopping Paço Alfândega, que se encontra em fase de recuperação para abrigar seis salas de cinema. Essa iniciativa, do mesmo empreendedor do mencionado Shopping, integra também o Monumenta BID.

Enfim, os edifícios do complexo Porto Digital, o Shopping Paço Alfândega e o Chantecler vêm provocando e provocarão ainda mais um fluxo excessivo e diferenciado de pessoas, cuja modalidade de deslocamento tem sido e, provavelmente, continuará a ser, no curto e médio prazo, o transporte individual. Isso tem contribuído 
para o agravamento das condições de circulação e de estacionamento. Até hoje, o Bairro, uma pequena ilha, não conta com um estudo que defina a sua capacidade de carga.

Não se pode deixar de realçar que o centro histórico de qualquer cidade se configura como um espaço público por excelência, não no sentido do que se convenciona denominar espaços públicos (praças, ruas, avenidas, calçadas...), mas no sentido de que é portador de um grande significado público, convertendo-se em um espaço diferenciado ao se tornar referência local, significado ainda maior quando se trata de uma referência nacional, como é o caso de parte significativa do Bairro do Recife. Não sem razão, Carrión (2001) afirma que o centro histórico

vive mais além do centro espaço e mais além do presente o tempo. Isso significa que sua condição pública transcende o tempo antigo, moderno e o espaço centro-perferia -, produzindo um legado transgeracional e transterritorial, que produz uma cidadania derivada por herança.

A tendência é prosseguir com essa orientação. Recentemente (2005), a uns duzentos metros da ponte sul de entrada na ilha, foi aprovado, também após debates no âmbito do CDU, o projeto de duas torres com 39 pavimentos (ver Figura 5), destinados a servir de residência para a elite da elite local, projeto que agride enormemente os padrões urbanísticos de vizinhança, comprometendo de forma irreversível a paisagem do conjunto arquitetônico e histórico do bairro de São José e, também, do Bairro do Recife e de Santo Antônio, que contam com inúmeros imóveis tombados pelo Iphan. Além disso, contribuirá, para incrementar o trânsito de veículos e o fluxos de pessoas, aproximando-se, ainda mais, do modelo de city marketing. 


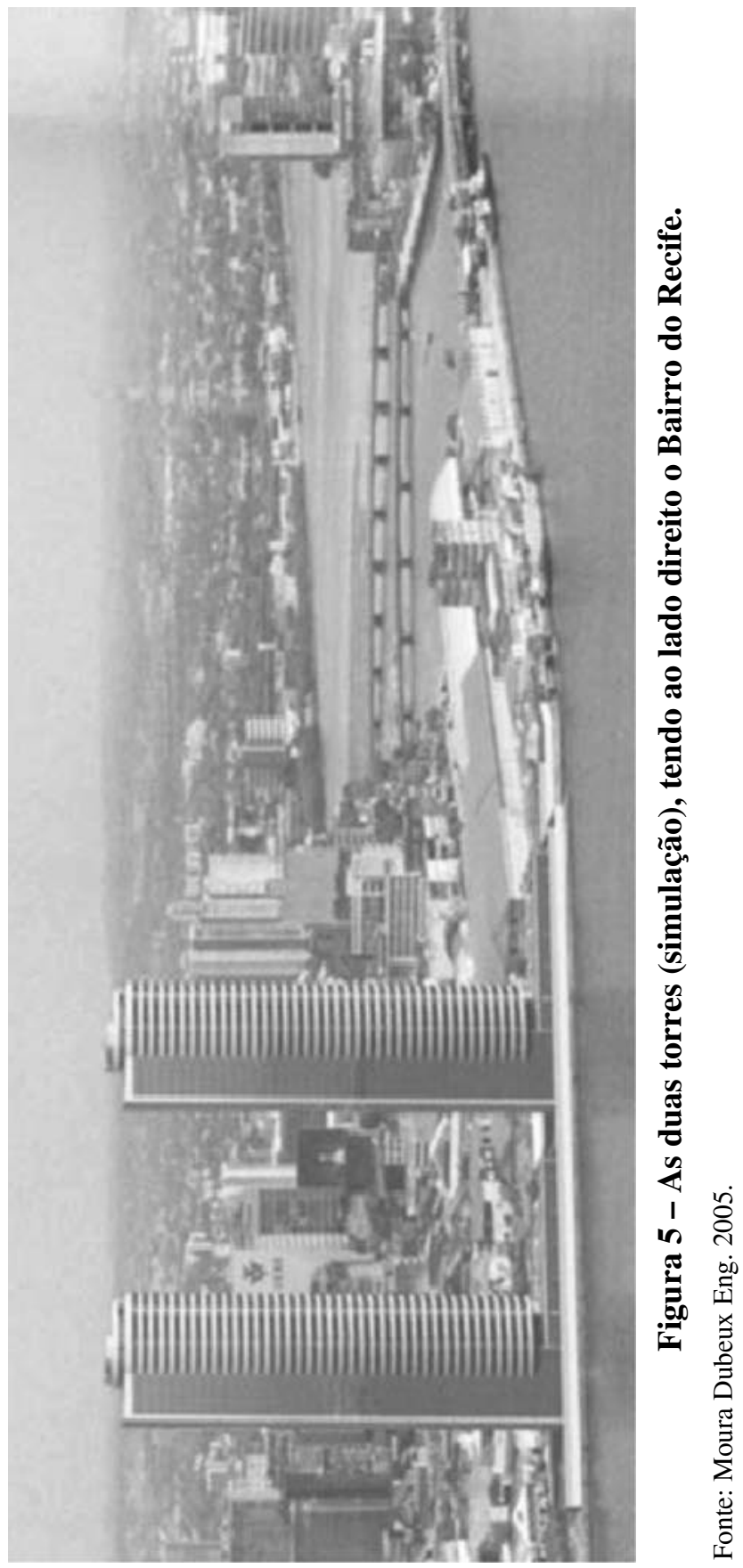


A grande diferença entre o edifício-garagem e essas torres é que, neste último caso, há uma luz no fundo do poço, uma vez que o Ministério Público Federal (MPF) em Pernambuco conseguiu, em dezembro de 2006, no Superior Tribunal de Justiça paralisar as obras, até o julgamento final da Ação Civil Pública, proposta em março de 2005. Esta Ação solicita que se torne sem efeito a aprovação da construção das duas torres concedida pelo município do Recife. O MPF alega que a obra, situada em área de casario baixo e próxima a inúmeros bens tombados, vai afetar a visibilidade dos bens de valor histórico e a harmonia do conjunto urbano local, em desrespeito ao Decreto-lei nº 25, de 1937.

O caso do edifício-garagem e das duas torres impulsionaram o questionar sobre a legitimidade dessas intervenções. Para responder, é importante que fiquem evidentes as diferenças conceituais entre legalidade e a legitimidade, particularmente quando se trata de intervir no espaço urbano.

\section{Legalidade e legitimidade das intervenções nas estruturas espaciais urbanas ${ }^{3}$}

Não se pode deduzir, automaticamente, que ações respaldadas na legalidade sejam legítimas. A legalidade, na sua acepção etimológica, é a qualidade da conduta que obedece a alguma lei. Significa, portanto, a existência de leis e a submissão a elas dos atos de todos aqueles que lhe estão sujeitos. No entanto, "a observância formal da legalidade externa não exclui incondicionalmente a injustiça de uma ação que, embora podendo ser legal, não deixaria em certos casos de ser, no fundo, ilegítima" (Dicionário de Ciências Sociais, p. 673).

Para um aprofundamento do conceito de legitimidade é pertinente recorrer a Noberto Bobbio (1986, p. 675-679). De acordo 
com esse pensador, o termo legitimidade designa tanto uma situação quanto um valor de convivência social. O valor é, por sua vez, o consenso livremente manifestado de uma parcela significativa de uma comunidade de pessoas autônomas e conscientes. Mais ainda, a legitimidade não é estática nem dinâmica, é uma unidade aberta cuja concretização deve ser considerada num futuro possível, ainda indefinido, e a realidade concreta nada mais é do que um esboço desse futuro. Assim, a legitimidade existe enquanto potencial, projetando-se para o futuro a partir da realidade concreta atual.

Esse potencial, entendido como o consenso livremente manifestado nos termos acima referidos, ocorre no processo político. Considerando esse processo e, para tanto, acompanhando Max Weber - ao examinar as bases sociais e ideológicas dos sistemas de domínio, esse sociólogo focaliza a aplicação ampla do princípio da legitimidade a sistemas de poder -, existem três tipos de poder legítimo, fundamentados em três tipos de motivações: (i) as tradições e os costumes, provenientes da força daquilo que dura há tempo, daquilo que sempre existiu e, desde que sempre existiu, não conhece razões para ser alterado; (ii) os procedimentos legais, derivados da crença na racionalidade do comportamento conforme a lei; e, (iii) o carisma, oriundo da crença dos dotes extraordinários de um chefe. Weber não excluía a possibilidade de relação entre uns e outros, admitindo ser difícil estabelecer onde começa um e termina o outro (apud. Bobbio, 1987, p. 93).

Ora, se um dos tipos de motivação é fundamentado nas tradições e nos costumes, aquele potencial, ocorre também no processo espacial. Considerando esse processo, pode-se admitir que intervenções urbanas que desconhecem as tradições e os costumes - pressupostos no processo tipológico principal, ou seja, na forma dominante da estrutura espacial urbana - vão de encontro a um dos princípios do processo real de legitimação, ao causar uma ruptura ou descontinuidade das tradições e costumes (Lacerda \& Abílio, 2005, p. 3). Afinal, como afirmam Remy e Voye (1992 p. 25): 
existe um laço biunívoco entre a estrutura espacial e a estrutura social ao ponto que - como demonstra Levi-Strauss com o exemplo dos Bororos -, caso se desmanche a estrutura espacial, se desorganiza no mesmo golpe os princípios de base do agir coletivo. O espaço é a formalização maior da cultura do grupo e de suas regras de funcionamento social.

Haveria, portanto, uma legitimidade cujos fatores determinantes se encontram na própria dimensão espacial. Sendo assim, um sistema de ações legítimo em relação ao espaço urbano pressupõe um processo que reconheça esse laço biunívoco entre a estrutura espacial e a estrutura social.

No Bairro do Recife e no seu entorno, as suas estruturas espaciais estão sendo alteradas, ocasionando o desaparecimento de determinada ordem espacial, responsável por práticas sociais mais democráticas - espaço de encontro - e pela emergência de outras, definidas por uma minoria que se utiliza de edifícios-garagem, habita em condomínios (horizontais ou verticais) de luxo e compra em shopping centers. Isso vem colocando em jogo as tradições e os costumes - pressupostos no processo tipológico principal -, um dos tipos de motivação que, como visto, impulsiona as ações consideradas como legítimas. Há, portanto, não apenas um laço biunívoco entre estrutura espacial e estrutura social, mas também entre estrutura espacial e legitimidade das ações. Nesse caso, por que não se falar em processos espacialmente legítimos ou ilegítimos?

\section{Conclusões}

As considerações acima levam a concluir que o processo de revitalização do Bairro do Recife, particularmente nos últimos 8 anos, vem ocorrendo de forma desordenada no que se refere à conservação da autenticidade do patrimônio histórico. O Plano elaborado em 1992 deveria ter sido revisto após os seus 5 primeiros 
anos de implementação, mas nada foi feito nesse sentido. Uma gestão compartilhada, como está previsto na Lei de Uso e Ocupação do Bairro do Recife, não se realizou. Permaneceu letra morta. Assim, não foi implementado um processo que garantisse a participação de todos os sujeitos patrimoniais.

Pode-se, também, afirmar que a política adotada vem sendo orientada para o atendimento das necessidades dos consumidores de mais alta renda da estrutura social da metrópole recifense, dos empresários e dos turistas, significando um desvirtuamento dos objetivos do Plano, particularmente no que se refere à transformação do Bairro em um centro de comércio, de lazer e de cultura que atenda aos interesses da maioria dos recifenses.

Mesmo considerando que as recentes intervenções no Bairro - o edifício-garagem - e no seu entorno - as duas torres - foram aprovadas pelas instâncias municipais competentes, elas não são espacialmente legítimas. O bairro vem sendo (re)organizado, impondo uma nova ordem espacial: a da elite metropolitana recifense, com o seu modo particular de produzir e se apropriar de certos espaços da cidade.

$\mathrm{Na}$ verdade, o que vem ocorrendo nesse bairro é o desconhecimento de que a preservação dos valores patrimoniais depende de sua democratização, isto é, de sua apropriação social, de sua promoção como interesse da maioria da população, da construção de um projeto coletivo e do fortalecimento do sentido de cidadania.

\section{Notas}

1 A recuperação das primeiras idéias para a conservação de áreas históricas foi, em grande parte, fundamentada no texto de Zancheti e Lacerda (1998).

2 Ibid. 
3 Sobre o conceito de legitimidade, aplicado a processos espaciais urbanos, ver, também, Lacerda e Abilio, (2005).

\section{Interventions in Recife's neighbourghood and surroundings: investigations of legitimacy}

Abstract: The aim of this article is (i) to demonstrate how the revitalization experience of the Bairro do Recife was deviated following the city marketing tendency, understood as the rising rate of transformation of certain localities, placing emphasis on speculation in buildings and works of famous architects, with serious repercussions for the flow of vehicles and people, and (ii) to question the legitimacy of projects that, although institutionally approved, compromise the characteristics of certain urban spatial structures such as historic centers.

Keywords: historical heritage, spatial legitimacy, Bairro do Recife

\section{Referências}

ACCIOLY, M. As passarelas do Recife. Jornal do Commercio, Recife, 11 de agosto de 2003.

BOBBIO, N. Estado, governo e sociedade. São Paulo: Paz e Terra, 1987.

BOBBIO, N.; MATTEUCCI, N.; PASQUINO, G. (Orgs.). Dicionário de Política. Brasília: UNB, 1986.

CARRIÓN, F. Centro histórico: relación social, globalización y mitos. In: POSSO, A. M. C. (Comp.). Políticas y gestión para la sostenibilidad del patrimônio. Bogotá: CEJA, 2001. p. 25-53.

CASTRIOTA, L. B. Intervenções sobre o patrimônio urbano: modelos e perspectivas. [s.d.]. [não publicado].

DICIONÁRIO de ciências sociais. Rio de Janeiro: Editora da Fundação Getúlio Vargas, 1986. 
MP vai à Justiça contra prédios já licenciados. Jornal do Comércio. Recife, 11 mar. 2005.

LACERDA, N., ABILIO, P. The conservation of urban structures: speculations on political and spatial legitimacy. City \& Time, v.1, p. 1-6, 2005.

LACERDA, N.; ZANCHETI, S. Planejamento metropolitano: uma proposta de conservação urbana e territorial. Revista Latinoamericana de Estudios Urbanos Regionales, Santiago do Chile, v. 26, n. 79, p. 77-94, 2000.

LAROCHELLE, P.; IAMANDI, C. Continuity and change in anthropic environments: toward a control based on the knowledge of historical transformation processes. In: ZANCHETI, S. M. (Ed.). Conservation and Urban Sustainable Development: a Theoretical Framework. Recife: Universitária da UFPE, 1999. p. 93-102.

MARINHO, G.; BOTLER, M. Modelo de regulação do Plano de Revitalização do Bairro do Recife. In: ZANCHETI, S.; MARINHO, G.; LACERDA, N. (Orgs.). Revitalização do Bairro de Recife: plano, regulação e avaliação. Recife: Editora Universitária da UFPE, 1998. p. 63-80.

MOURA DUBEUX ENGENHARIA. Recife Antigo, Recife Moderno, V. 2, n. 9, 2005.

OSTROWETSKY, S. L'imaginaire bâtisseur: les villes nouvelles françaises. Paris: Librairie des Méridiens, 1983.

REMY, J.; VOYE, L. La ville: vers une nouvelle definition? Paris: L'Harmattan, 1992.

SECCHI, B. Un progetto per l'urbanistica. Torino: Einaudi, 1998.

ZANCHETI, S.; LACERDA, N. O desempenho do Plano de Revitalização do Bairro do Recife. In: ZANCHETI, S.; MARINHO, G.; LACERDA, N. (Orgs.). Revitalização do Bairro de Recife: plano, regulação e avaliação. Recife: Editora Universitária da UFPE, 1998. p. 89-135. 